\title{
Age-Dependent MicroRNA Control of Synaptic Plasticity in 22q11 Deletion Syndrome and Schizophrenia
}

\author{
Laurie R. Earls, R. Gaines Fricke, Jing Yu, Raymond B. Berry, Lisa T. Baldwin, and Stanislav S. Zakharenko \\ Department of Developmental Neurobiology, St. Jude Children's Research Hospital, Memphis, Tennessee 38105
}

The 22q11 deletion syndrome (22q11DS) is characterized by multiple physical and psychiatric abnormalities and is caused by the hemizygous deletion of a 1.5-3 Mb region of chromosome 22. It constitutes one of the strongest known genetic risks for schizophrenia; schizophrenia arises in as many as 30\% of patients with 22q11DS during adolescence or early adulthood. A mouse model of 22q11DS displays an age-dependent increase in hippocampal long-term potentiation (LTP), a form of synaptic plasticity underlying learning and memory. The sarco(endo)plasmic reticulum $\mathrm{Ca}^{2+}$ ATPase (SERCA2), which is responsible for loading $\mathrm{Ca}^{2+}$ into the endoplasmic reticulum (ER), is elevated in this mouse model. The resulting increase in ${\mathrm{ER} \mathrm{Ca}^{2+}}^{2+}$ load leads to enhanced neurotransmitter release and increased LTP. However, the mechanism by which the 22q11 microdeletion leads to SERCA2 overexpression and LTP increase has not been determined. Screening of multiple mutant mouse lines revealed that haploinsufficiency of Dgcr8, a microRNA (miRNA) biogenesis gene in the 22q11DS disease-critical region, causes age-dependent, synaptic SERCA2 overexpression and increased LTP. We found that miR-25 and miR-185, regulators of SERCA2, are depleted in mouse models of 22q11DS. Restoration of these miRNAs to presynaptic neurons rescues LTP in $D \mathrm{gcr}^{+/-}$mice. Finally, we show that SERCA2 is elevated in the brains of patients with schizophrenia, providing a link between mouse model findings and the human disease. We conclude that miRNA-dependent SERCA2 dysregulation is a pathogenic event in 22q11DS and schizophrenia.

\section{Introduction}

Schizophrenia affects $\sim 1 \%$ of the world's population and is characterized by symptoms that include hallucinations and delusions (positive symptoms), antisocial behavior and blunted emotions (negative symptoms), and deficits in working memory, executive function, and learning and memory (cognitive symptoms). Mechanisms of schizophrenia are poorly understood, in part because no single gene mutation is associated with development of the disease. Consequently, research in genetic models of schizophrenia has been difficult to interpret (Nestler and Hyman, 2010).

One well known genetic predictor of schizophrenia is the $22 \mathrm{q} 11$ deletion syndrome (22q11DS). This syndrome is caused by

Received March 6, 2012; revised June 22, 2012; accepted July 25, 2012.

Author contributions: L.R.E. and S.S.Z. designed research; L.R.E., R.G.F., J.Y., L.T.B., and R.B.B. performed research; L.R.E. and S.S.Z. wrote the paper.

This work was supported in part by National Institute of Mental Health Grants R01MH079079, R01MH095810 (S.S.Z.) and the American Lebanese Syrian Associated Charities. We thank Dr. Elizabeth Illingworth (Dulbecco Telethon Institute) for providing Df(16)2/+ mice, Dr. Anthony Wynshaw-Boris (University of California San Francisco) for providing Znf74I-Ctp/+ mice, Dr. Joseph Gogos (Columbia University) for providing Comt ${ }^{+/-}$and Prodh ${ }^{+/-}$ mice, and Dr. Stephen Strittmatter (Yale University) for providing $R t n 4 r^{+/-}$mice for this study. We also thank the Harvard Brain Tissue Resource Center, which is supported in part by Public Health Service Grant R24MH068855, and Dr. Vahram Haroutunian (The Mount Sinai School of Medicine) for providing postmortem human brain samples. L.T.B. was supported in part by Grant 5R25CA023944 from the National Cancer Institute. We thank Dr. John Gray and the St. Jude Vector Core for producing AAVs, Granger Ridout and the St. Jude Hartwell Center for Bioinformatics for performing microarrays, and Vani Shanker for editing this manuscript. The funding sources had no role in study design, data collection and analysis, decision to publish, or preparation of this manuscript.

The authors declare no competing financial interests.

Correspondence should be addressed to Dr. Stanislav S. Zakharenko, Department of Developmental Neurobiology, MS 323, St. Jude Children's Research Hospital, 262 Danny Thomas Place, Memphis, TN 38105-3678. E-mail: stanislav.zakharenko@stjude.org.

DOI:10.1523/JNEUROSCI.1312-12.2012

Copyright $\odot 2012$ the authors $\quad 0270-6474 / 12 / 3214132-13 \$ 15.00 / 0$ the hemizygous deletion of a 1.5-3-megabase region of the $\mathrm{q}$ arm of chromosome 22, resulting in the haploinsufficiency of 30-40 genes (Scambler et al., 1992; Burn et al., 1993; Ryan et al., 1997; Scambler, 2000; Oskarsdóttir et al., 2004). Schizophrenia develops in $~ 30 \%$ of patients with 22q11DS during adolescence or early adulthood (Pulver et al., 1994; Bassett et al., 2005; Chow et al., 2006). Symptoms of 22q11DS-related schizophrenia are indistinguishable from those of the idiopathic disease (Pulver et al., 1994; Murphy et al., 1999; Chow et al., 2006), suggesting that lessons learned from deletionrelated forms of schizophrenia may also shed light on the mechanisms of schizophrenia in general.

Cognitive deficits are central to schizophrenia and are among its least treatable symptoms (Green, 1996; Green et al., 2000; Gold, 2004). Cognitive deficits have been linked to the hippocampus (Heckers et al., 1998; Weinberger, 1999; Tamminga et al., 2010), a brain region central to learning and memory. Synaptic plasticity at excitatory synapses is a mechanism of hippocampus-related learning and memory (Milner et al., 1998; Martin et al., 2000) that provides an excellent means to probe cellular events related to cognition in animal models of schizophrenia.

The 22q11DS-critical region is largely conserved on mouse chromosome 16, allowing for the generation of 22q11DS mouse models. $D f(16) 1 /+$ mice carry a hemizygous deletion of 23 genes in the syntenic region of chromosome 16 (Lindsay et al., 1999) and develop a spatial memory deficit and enhanced synaptic plasticity in the form of long-term potentiation (LTP) by 16 weeks (Earls et al., 2010). This age-dependent alteration is caused by an aberrant increase in the level of sarco(endo)plasmic reticulum 
ATPase (SERCA2), which maintains $\mathrm{Ca}^{2+}$ levels in the endoplasmic reticulum (ER). SERCA2 upregulation increases LTP by enhancing $\mathrm{Ca}^{2+}$ entry into the presynaptic cytoplasm and releasing excessive neurotransmitter during synaptic plasticity induction (Earls et al., 2010). Age-dependent synaptic abnormalities in $D f(16) 1 /+$ mice may affect the cognitive decline observed at the onset of schizophrenia. Identification of the culprit genes within the 22q11DS-critical region that cause these abnormalities may provide new insight into the disease's pathophysiology.

Here we used a panel of mutant mice carrying hemizygous deletions of genes within the 22q11DS-critical region to screen for genes involved in the age-dependent increase in LTP. This screen identified $D g c r 8$ deficiency as a contributor to synaptic abnormalities. The hemizygous loss of Dgcr 8 causes an agedependent increase in LTP that depends on the synaptic upregulation of SERCA2. We also provide evidence that SERCA2 is upregulated in postmortem brain samples from patients with schizophrenia. We propose that the molecular events described in these mouse models of 22q11DS may be relevant to the human disease.

\section{Materials and Methods}

Animals. Young (8-10 weeks) and mature (16-20 weeks) mice of both sexes were used for all experiments except the microarray experiments, for which only male mice were used. $\mathrm{Dgcr} 8^{+/-}$mice were generated from the XH157 ES cell line (Bay Genomics) as previously described (Stark et al., 2008; Schofield et al., 2011). $Z d h h c 8^{+/-}$mice were generated from the IST14452C2 ES cell line (TIGM), which contains a gene-trap insertion downstream of the first exon. To expand the colony, $\mathrm{Dgcr} 8^{+/-}$and $Z \mathrm{dhhc8^{+/- }}$ mice harboring the disrupted alleles were bred to $\mathrm{C} 57 \mathrm{BL} / 6 \mathrm{~J}$ mice in our animal-housing facility. Production and genotyping of $D f(16) 1 /+$ (Lindsay et al., 1999), $D f(16) 2 /+$ (Lindsay et al., 2001), Znf74l-Ctp/+(Kimber et al., 1999), Prodh $^{+/-}$(Gogos et al., 1999), Comt $^{+/-}$(Gogos et al., 1998),

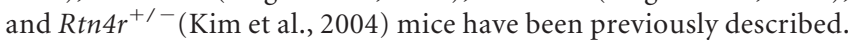
All mouse strains in this study were back-crossed onto the C57BL/6J genetic background for at least six generations. The care and use of animals was reviewed and approved by the St. Jude Children's Research Hospital Institutional Animal Care and Use Committee.

Electrophysiology. Acute transverse hippocampal slices $(400 \mu \mathrm{m})$ were prepared as previously described (Earls et al., 2010). Briefly, mouse brains were quickly removed and placed in cold $\left(4^{\circ} \mathrm{C}\right)$ dissecting artificial CSF (ACSF) containing the following (in $\mathrm{mM}$ ): 125 choline-Cl, $2.5 \mathrm{KCl}$, $0.4 \mathrm{CaCl}_{2}, 6 \mathrm{MgCl}_{2}, 1.25 \mathrm{NaH}_{2} \mathrm{PO}_{4}, 26 \mathrm{NaHCO}_{3}$, and 20 glucose (285$295 \mathrm{mOsm}$ ), under $95 \% \mathrm{O}_{2} / 5 \% \mathrm{CO}_{2}$. After dissection, slices were incubated for $1 \mathrm{~h}$ in ACSF containing the following: (in mM): $125 \mathrm{NaCl}, 2.5$ $\mathrm{KCl}, 2 \mathrm{CaCl}_{2}, 2 \mathrm{MgCl}_{2}, 1.25 \mathrm{NaH}_{2} \mathrm{PO}_{4}, 26 \mathrm{NaHCO}_{3}$, and 10 glucose (285-295 mOsm), under $95 \% \mathrm{O}_{2} / 5 \% \mathrm{CO}_{2}$ at room temperature, and then transferred into submerged recording chambers and superfused $(2-3 \mathrm{ml} / \mathrm{min})$ with warm $\left(30-32^{\circ} \mathrm{C}\right)$ ACSF. Field recordings were performed using a setup with eight submerged recording chambers (Campden Instruments). Recordings in each chamber were performed independently. Field EPSPs (fEPSPs) from the CA1 stratum radiatum were recorded by using an extracellular glass pipette $(3-5 \mathrm{M} \Omega$ ) filled with ACSF. Schaffer collateral fibers in the stratum radiatum were stimulated with a bipolar tungsten electrode placed 200-300 $\mu \mathrm{m}$ away from the recording pipette. Stimulation intensities were chosen to produce an fEPSP with a $0.5 \mathrm{~V} / \mathrm{s}$ slope. LTP was induced by three periods of $200 \mathrm{~Hz}$ tetanization delivered every $5 \mathrm{~min}$. Each period of tetanization consisted of 10 trains of $200 \mathrm{~Hz}$ stimulation delivered at the same intensity for 200 ms (40 stimulations) every $5 \mathrm{~s}$.

Western blotting. Western blots were performed as previously described (Earls et al., 2010). For human brain tissue, dissected samples arrived from brain banks frozen on dry ice. Mouse tissue was dissected at $4^{\circ} \mathrm{C}$ and prepared either as whole-tissue lysates or as crude P2 synaptosomal fractions. Synaptosomes were prepared as described previously (Gray and Whittaker, 1962). In brief, tissue was homogenized in $10 \mathrm{~mm}$
HEPES ( $\mathrm{pH}$ 7.4)/0.32 м sucrose using a motorized glass-Teflon homogenizer. To separate the P2 synaptosomal fraction, the homogenate was spun for $5 \mathrm{~min}$ at $800 \times g$; the supernatant from three successive spins was then centrifuged for $20 \mathrm{~min}$ at $12,000 \times g$. Tissue or synaptosomal pellets were lysed by freezing and thawing, subsequent syringe passage in ice-cold radioimmunoprecipitation assay buffer $(50 \mathrm{~mm}$ Tris- $\mathrm{HCl}[\mathrm{pH}$ 7.4], $1 \%$ NP-40, $0.25 \%$ sodium deoxycholate, $150 \mathrm{~mm} \mathrm{NaCl}, 1 \mathrm{~mm}$ EDTA, and protease inhibitor cocktail tablets (Roche), and finally brief sonication. Concentrations of protein lysates were determined by the BCA assay (Thermo Scientific). A $25 \mu \mathrm{g}$ sample of each protein extract was electrophoresed on a 10\% SDS-PAGE gel, and protein was transferred onto polyvinylidene difluoride membranes (Invitrogen). The primary antibodies used were goat anti-SERCA2 (1:250, sc-8095; Santa Cruz Biotechnology) and mouse anti- $\beta$-actin (1:10,000, A5316; Sigma-Aldrich). SERCA and $\beta$-actin Western blots were probed with anti-mouse (1:5000) and anti-goat (1:5000) secondary antibodies conjugated to IR dye 680 or 800 (LI-COR Biosciences). These blots were imaged and quantified using the Odyssey infrared imaging system (LI-COR Biosciences).

MicroRNA microarray. Total RNA was isolated from 4-month-old male wild-type (WT) and $D f(16) 1 /+$ hippocampi using the miRVana RNA isolation kit (Ambion). A mouse miRNA microarray (Agilent-029298; Agilent Technologies) consisting of probes for 690 mouse miRNAs from the Sanger miRBase (release 14.0) was designed and manufactured by Agilent Technologies. Array hybridization was performed according to the manufacturer's recommended protocols. In brief, total RNA was labeled using the Agilent miRNA labeling kit. Hybridization was performed in an Agilent oven at $55^{\circ} \mathrm{C}$ for $20 \mathrm{~h}$ at $20 \mathrm{rpm}$, followed by standard wash procedures. The microarray was then scanned in an Agilent scanner at $5 \mu \mathrm{m}$ resolution, and the array data were extracted using the default miRNA settings of Agilent Feature Extraction Software (v10.5.1.1) with the miR 105_Jan09 protocol. Signal intensity was normalized at the 80th percentile, scaled across the sample set, and $\log _{2}$ transformed. The minimum detecting miRNA expression signal was set at a threshold greater than the 99th percentile of those from the negative-control probes. A $p$ value was calculated using a $t$ test of samples from two different experimental conditions.

Quantitative real-time PCR. Total RNA $(1 \mu \mathrm{g})$ was polyadenylated and reverse transcribed using an oligo-dT primer with an attached universal sequence tag according to the miRNA First-Strand cDNA Synthesis kit (Stratagene/Agilent). The qPCR was then performed using SYBR green (Applied Biosystems), a forward primer specific to the miRNA of interest: $\mathrm{mmu}$ miR185 (tggagagaaaggcagttcct), mmu-miR-299* (tggtttaccgtcccac), mmumiR-337-3p (ttcagctcctatatgatg), mmu-miR-411 (tagtagaccgtatagcgta), mmu-miR-411* (tatgtaacacggtccacta), mmu-miR-874 (ctggcccgagggacc), mmu-miR-374 (atataatacaacctgctaag), mmu-miR-379 (tggtagactatggaac gta), mmu-miR-337-5p (gaacggcgtcatgcaggag), mmu-miR-329 (aacacaccca gctaaccttt), mmu-miR-674* (cacagctcccatctcagaac), mmu-miR-323-3p (ta cagttgttcaaccagtta), mmu-miR-582-5p (tacagttgttcaaccagtta), mmumiR-98 (tgaggtagtaagttgtattg), mmu-miR-672 (tgaggttggtgtactgtgtgt), mmu-miR-421 (atcaacagacattaattgggc), mmu-miR-409-5p (aggttacccgagca actttgc), mmu-miR-872 (aaggttacttgttagttca), mmu-miR-532-3p (cctcccac acccaaggcttg), mmu-miR-425 (aatgacacgatcactcccgtt), mmu-miR-25 (cattgc acttgtctcggtct), U6snRNA_Forward (cgcttcggcagcacatatac), U6snRNA_ Reverse(ttcacgaatttgcgtgtcat), and a universal reverse primer specific to the sequence tag (miRNA First-Strand cDNA Synthesis kit, Stratagene/Agilent). qPCR was performed in an Applied Biosystems 7900HT Fast Real-Time PCR System using the following cycling parameters: $55^{\circ} \mathrm{C}(2 \mathrm{~min}), 95^{\circ} \mathrm{C}(10$ $\mathrm{min}), 40$ cycles of $95^{\circ} \mathrm{C}(15 \mathrm{~s}), 60^{\circ} \mathrm{C}(30 \mathrm{~s})$, and $72^{\circ} \mathrm{C}(20 \mathrm{~s})$. miRNA concentrations were calculated using cycle threshold values and a standard curve made from serial dilutions of WT cDNA samples (dilutions: 1:3, 1:9, 1:27, 1:81, 1:243, 0). The control, U6 snRNA [primers used from (Thomson et al., 2006)], showed no difference between WT and $D f(16) 1 /+$ samples. Therefore, all miRNA concentrations were normalized to the U6 level for a given animal. All PCR experiments were conducted in duplicate. PCR products were run on a $5 \%$ polyacrylamide gel to confirm the presence of a single band of the expected size, and PCR products were cloned and sequenced to confirm the identity of each miRNA. Mature forms of miRNAs produced a 
single band $\sim 80$ bp in size in agreement with estimations (22 bp miRNA + polyA tail of varying size +32 bp universal tag sequence) (data not shown).

In vivo viral injections. Adeno-associated viruses (AAVs) were made by cloning chimeric hairpins of the miRNAs of interest with hsa-miR$30 \mathrm{a}$ into the pAAV-6P-SEWB vector, as previously described (Christensen et al., 2010). The following primers were used: ChimericmiR185up1 (gtacagctgttgacagtgagcgac tggagagaaaggcagttcctgatgtgaa), Chimericmi R185up2 (gccacagatggtcaggaactctttctctccagctgcct actgcctcggaa), ChimericmiR185low1 (ccatctgtgg cttcacatcaggaactgcctttctctccagtcgctcactgtcaaca gct),ChimericmiR185low2 (agctttccgaggcagtaggc agctggagagaaagagttcctga), ChimericmiR25up1 (gt acagctgttgacagtgagcgacaggcggagacttgggcaattgctg tgaa), ChimericmiR25up2 (gccacagatgggcaattgcc agtctccgctgctgcctactgcctcggaa), Chimericmi R25low1 (ccatctgtggcttcacagcaattgcccaagtctccgec tgtcgctcactgtcaacagct), and ChimericmiR25low2 (agctttccgaggcagtaggcagcaggcggagactggcaattgc).

Viruses were prepared by cotransfecting each plasmid into HEK293 cells with both pDp1 and pDp2 helper plasmids. AAVs were then harvested and purified as previously described (Zolotukhin et al., 1999). Titers were in the range of $10^{11} \mathrm{TU} / \mathrm{ml}$. Anesthesia in mice (10 weeks of age) was induced with $2-2.5 \%$ isoflurane (in $100 \% \mathrm{O}_{2}$ ). Anesthesia was maintained during surgery using $1.5 \%$ isoflurane. A $1 / 32-G$ cannula was inserted into the brain to deliver $2 \mu \mathrm{l}$ AAV-miRNA or AAV-empty in three locations centered on the $\mathrm{CA} 3$ region of the hippocampus (AP: $-1.8 \mathrm{~mm}$; $: \pm 2.4 \mathrm{~mm}$; $\mathrm{V}:-2.0 \mathrm{~mm}$ ). AAV-miRNA was injected into one hemisphere, and green fluorescent protein (GFP)-only control AAV was injected into the contralateral hemisphere. Following AAV injections, incisions were sutured, and mice were allowed to recover and were then returned to holding cages. Electrophysiological and imaging experiments in hippocampal slices from these mice were performed 6-8 weeks after $\mathrm{AAV}$ injections.

\section{Spatial memory testing}

We tested spatial memory in the Morris water maze as previously described (Earls et al., 2010). Briefly, animals learned to find a platform hidden under water clouded with nontoxic, water-based paint. The platform was located in the same "training quadrant" of the pool, and mice learned to locate its position using the standard version of the Morris water maze spatial learning task for 10 successive days. A spatial memory probe trial was administered on the day after the completion of spatial learning. With the platform removed, animals received a single $1 \mathrm{~min}$ trial in which they tried to find the escape platform in the training quadrant. This trial started from the point that was the farthest from the platform's location on the previous training day. The overall path length was measured for each mouse, and the relative path length for each quadrant was calculated.

Human brain tissue. Postmortem samples of human prefrontal cortex were obtained from the Alzheimer Disease and Schizophrenia Brain Bank (Mount Sinai School of Medicine, New York, NY). Samples from 17 patients with schizophrenia and 22 unaffected controls were used. Postmortem samples of human hippocampus were obtained from the Harvard Brain Tissue Resource Center (McLean Hospital, Belmont, MA). Samples from five patients with schizophrenia and six age-matched unaffected controls (all males) were used.
Drugs. Drugs were purchased from Sigma-Aldrich, except thapsigargin, which was purchased from Tocris Bioscience.

Statistical analyses. All data are represented as mean \pm SEM. Statistical analyses for all experiments were performed using nonparametric Man$n$-Whitney rank sum, Wilcoxon signed rank, or $t$ tests measured in Sigma Stat (Systat Software). Kruskal-Wallis one-way ANOVA by ranks was used to compare $>2$ independent groups.

\section{Results}

Age-dependent LTP increase in $\operatorname{Dgcr8}^{+/-}$mice

In the $D f(16) 1 /+$ mouse model of 22q11DS, LTP of synaptic transmission measured at excitatory hippocampal synapses between CA3 and CA1 pyramidal neurons (CA3-CA1 synapses) increases in mature (16-20 weeks) but not young ( $8-10$ weeks) animals (Earls et al., 2010). LTP was $>200 \%$ higher in mature $D f(16) 1 /+$ mice than WT littermates, whereas basal synaptic transmission at CA3-CA1 synapses in $D f(16) 1 /+$ mice was normal.

To narrow the location of genes involved in the LTP phenotype, we took advantage of mice that carry smaller hemizygous subdeletions within the $D f(16) 1$ region (Kimber et al., 1999; Lindsay et al., 2001). We tested basal synaptic transmission and LTP of fEPSPs in 
A

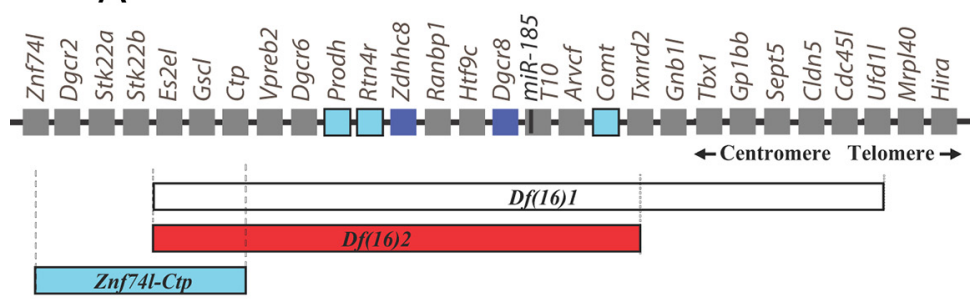

B
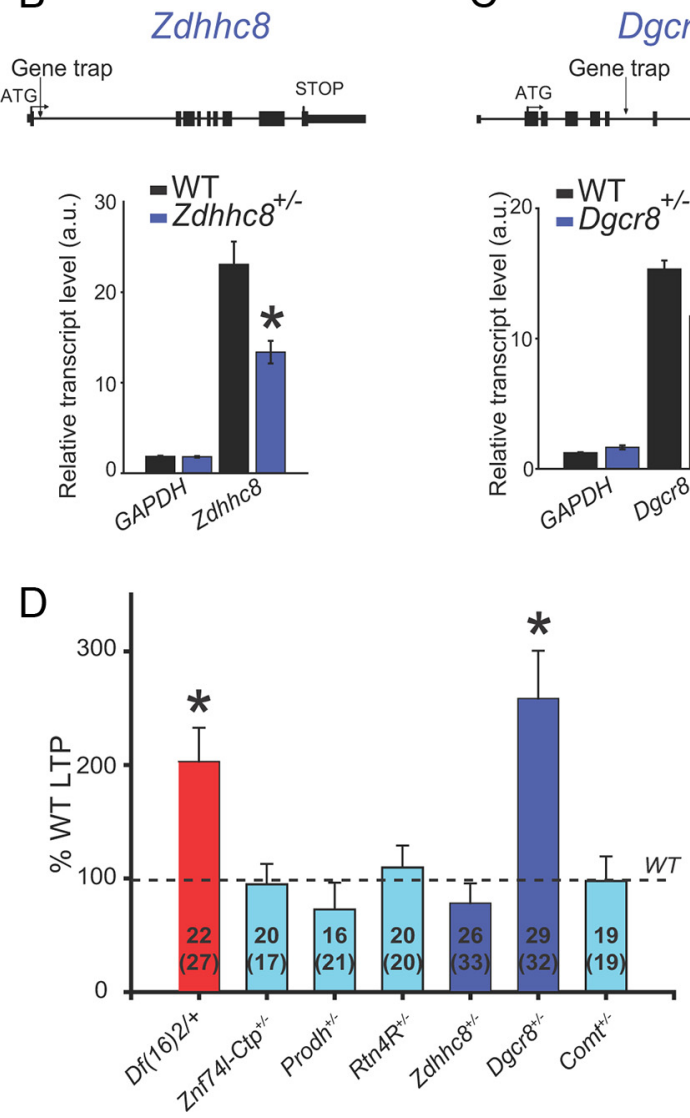

Figure 2. Heterozygous deletion of the $D f(16) 2$ gene $D g c r 8$ causes LTP increase at CA3-CA1 synapses. $A$, Diagram depicting genes from the 22q11 syntenic region that are implicated in synaptic function (dark and light blue). Horizontal bars represent genomic regions hemizygously deleted in $D f(16) 1 /+$ and $D f(16) 2 /+$ or Znf74l-Ctp/+ mice. Mice hemizygously deleted for Zdhhc 8 and Dgcr 8 (dark blue) were produced in this study. B, C, Diagrams of gene trap alleles to inactivate the Zdhhc 8 and Dgcr 8 genes in mice. Top, Map of gene-trap disruption of the Zdhhc8 gene in the IST14452C2 ES cell line $(\boldsymbol{B})$ and the Dgcr8 gene in the XH157 ES cell line (C). Bottom, qPCR analysis of Zdhhc8 levels in WT and Zdhhc $8^{+/-}$mice $(\boldsymbol{B})$ and Dgcr8 levels in WT and Dgcr8 ${ }^{+/-}$mice (C). D, Mean LTP levels in heterozygous mice relative to the LTP level in respective littermate WT controls for individual genes within the $D f(16) 2$ region. Numbers of slices from mutant mice and WT littermates (in parenthesis) are indicated inside the bars. ${ }^{*} p<0.01$.

acute hippocampal slices from $D f(16) 2 /+$ mice, which carry a hemizygous deletion of genes at the proximal end of the $D f(16) 1$ region (Es2el-Trxr2) (Fig. 1A). As in $D f(16) 1 /+$ mice, LTP was elevated in $D f(16) 2 /+$ animals in an age-dependent manner (Fig. $1 B, C$ ). In young animals, the increase in fEPSP slope (measure of LTP) quantified $6 \mathrm{~h}$ after tetanization of Schaffer collaterals was not significantly different between $D f(16) 2 /+$ and WT littermates $(D f(16) 2 /+: 20$ slices, 4 mice; WT: 23 slices, 5 mice; $p=0.238$ ). However, in mature $D f(16) 2 /+$ mice, LTP was higher than in WT littermates $(D f(16) 2 /+: 22$ slices, 6 mice; WT: 27 slices, 7 mice; $p=0.006)$ (Fig. $1 C)$. On average, LTP in $D f(16) 2 /+$ mice was $\sim 100 \%$ higher than that in WT littermates.
As in $D f(16) 1 /+$ mice, basal synaptic transmission was normal in both young and mature $D f(16) 2 /+$ mice (Fig. $1 D, E)$. Thus, the input-output relationship between fEPSPs and stimulation intensity was comparable in young and mature WT and $D f(16) 2 /+$ mice (young $D f(16) 2 /+$ : 20 slices, 4 mice; young WT: 23 slices, 5 mice, $p>0.05$; mature $D f(16) 2 /+: 22$ slices, 6 mice; mature WT: 27 slices, 7 mice, $p>0.05$ ).

Changes in LTP are often associated with changes in learning and memory. The substantial increase in LTP at CA3-CA1 synapses in mature $D f(16) 1 /+$ mice is accompanied by a mild deficit in hippocampus-dependent spatial memory, as measured in the Morris water maze task (Earls et al., 2010). In mature $D f(16) 2 /+$ mice, however, spatial memory tested in the Morris water maze task was normal (data not shown, $27 D f(16) 2 /+$ and 26 WT mice, $p=0.875$ ), indicating that additional genetic factors are required for the full effect on learning and memory (see Discussion).

To identify the culprit gene within the $D f(16) 2$ region, we further narrowed the LTP-critical region by measuring LTP in Znf74l-Ctp/+mice (Kimber et al., 1999), which carry a hemizygous, $150 \mathrm{~kb}$ subdeletion that includes the three most proximal $D f(16) 2$ genes Es2el, Gscl, and Ctp (Fig. 2A). LTP was normal in mature Znf74l-Ctp/ + mice compared with WT littermates (Fig. $2 D$ ), indicating that $E s 2 e l, G s c l$, and $C t p$ do not contribute to the phenotype observed in $D f(16) 2 /+$ mice. Among the remaining genes in the $D f(16) 2$ region, five have been previously implicated in the pathogenesis of 22q11DS and schizophrenia. To test whether these genes affect age-dependent LTP, we used mice deficient for these genes. These included $\operatorname{Prodh}^{+/-}$(Gogos et al.,

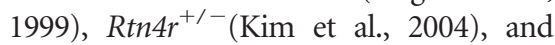
Comt $^{+/-}$(Gogos et al., 1998) mice and $Z d-$ $h h c 8^{+/-}$and $D g c r 8^{+/-}$mice (Fig. 2A), which were generated during the course of this study. $Z d h h c 8^{+/-}$and $D g c r 8^{+/-}$mice had significant reductions of the targeted genes, verifying haploinsufficiency of these genes in the heterozygous mutants (Figures $2 B, C)$. A comparison of LTP between mutants and WT littermates from each mutant line at 16 weeks of age revealed an LTP increase only in $D g c r 8^{+/-}$mice (Figures $2 D$, 3). Similar to $D f(16) 2 /+$ mice, the LTP increase in $\mathrm{Dgcr}^{+{ }^{+\prime}-}$ mutants was age dependent; there was no increase in LTP in WT littermates in 8- to 10-week-old animals $\left(D g c r 8^{+/-}: 31\right.$ slices, 7 mice; WT: 39 slices, 7 mice, $p=0.850$ ) (Figure $3 A)$. However, mature $D g c r 8^{+/-}$mice had increased LTP, which was equivalent to that of $D f(16) 2 /+$ mutants $\left(D g c r 8^{+/-}: 29\right.$ slices, 6 mice; WT: 32 slices, 7 mice, $p<0.001$ ) (Figs. $2 D, 3 B$ ). Input-output coupling did not differ between young (data not shown) and mature $\mathrm{Dgcr}^{+\prime-}$ and WT littermates, indicating that the hemizygous deletion of $D g c r 8$ does not affect basal synaptic transmission (Fig. $3 C$ ). 


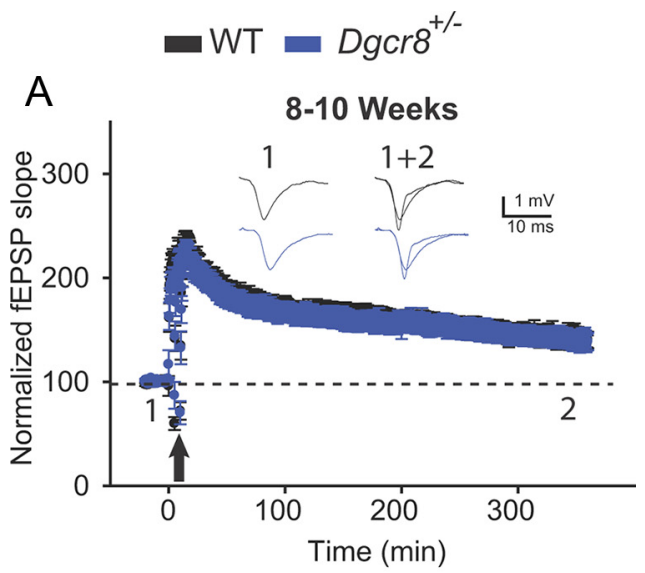

B

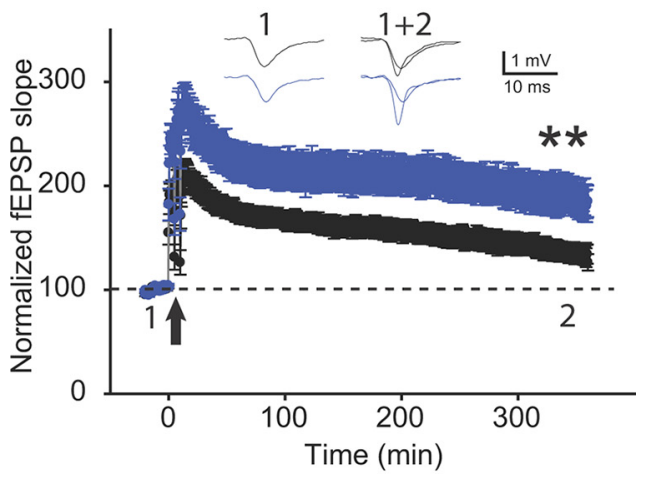

C

16-20 Weeks

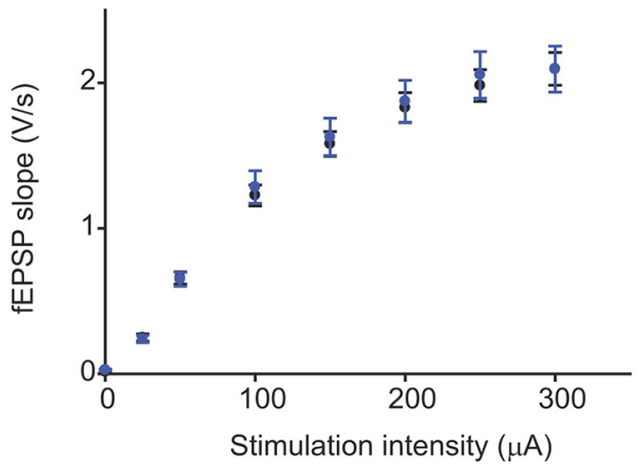

Figure 3. Heterozygous $D g c r 8$ deletion causes LTP increase in an age-dependent manner. $\boldsymbol{A}$, LTP is normal in young $D g c r 8^{+/-}$mice (blue). $B$, LTP is elevated in mature $D g c r 8^{+/-}$mice. Arrows indicate the onset of LTP induction. Insets show representative fEPSPs recorded before (1) and after (2) induction of LTP. C, Basal synaptic transmission is normal in mature Dgcr8 ${ }^{+/-}$ mice. Input- output coupling in Dgcr8 ${ }^{+/-}$and WT littermates. ${ }^{* *} p<0.001$.

These results implicate $D g c r 8$ as the gene from the $D f(16) 2$ region that is responsible for the observed abnormalities in synaptic plasticity.

\section{Age-dependent upregulation of SERCA2 in $\mathrm{Dgcr}^{+/-}$ hippocampus}

We previously showed that age-dependent overexpression of SERCA2 is crucial for the LTP increase observed in $D f(16) 1 /+$ mice (Earls et al., 2010). SERCA2 is increased in the hippocampus of mature but not young $D f(16) 1 /+$ mice, and SERCA inhibitors rescue the LTP increase in mature $D f(16) 1 /+$ mice (Earls et al., 2010). Therefore, we tested SERCA2 protein levels in the hip-
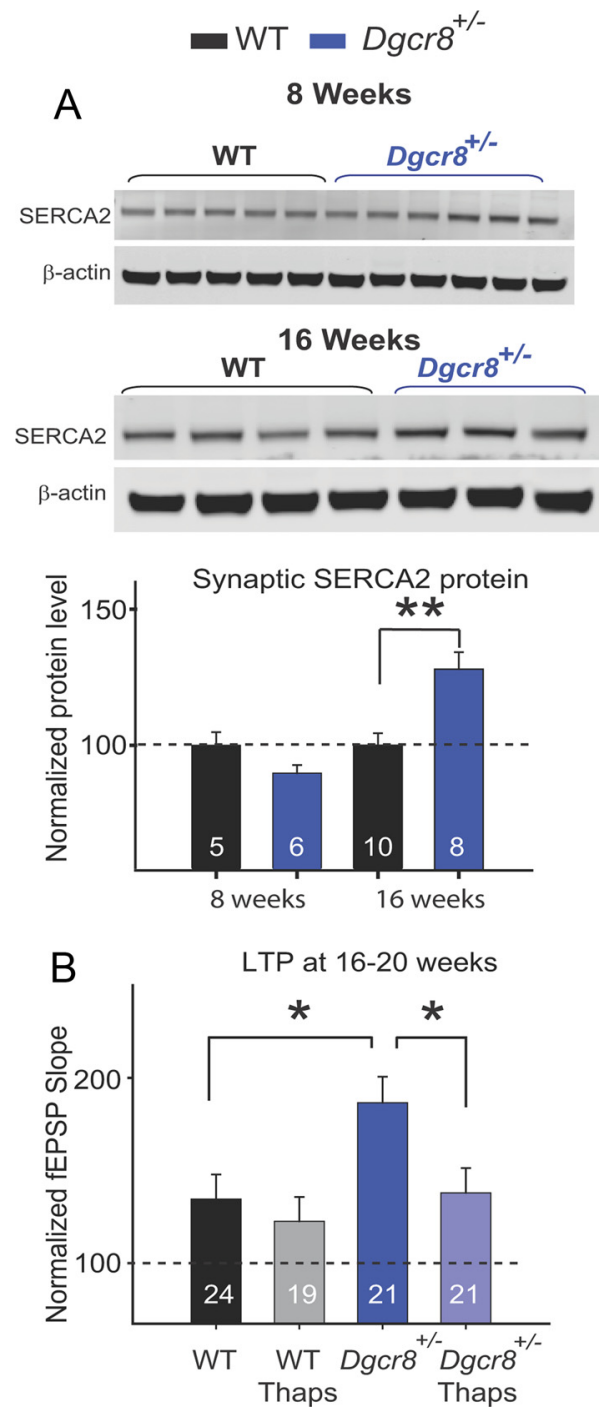

Figure 4. LTP increase caused by heterozygous Dgcr8 deletion is SERCA2-dependent. $\boldsymbol{A}$, Representative images of Western blots for SERCA2 in hippocampal synaptosomes extracted from young (top) or mature (middle) $D g c r 8^{+/-}$and WT mice. Bottom, Quantification of SERCA2 protein levels in young and mature $D g c r 8^{+/-}$and WT mice. SERCA2 protein levels were normalized to the level of $\beta$-actin protein. $\boldsymbol{B}$, Thapsigargin (Thaps) rescues the LTP increase in mature $D g c r 8^{+/-}$mice. Numbers of mice $(\boldsymbol{A})$ or slices $(\boldsymbol{B})$ are indicated inside the bars. ${ }^{*} p<$ $0.05 ;{ }^{* *} p<0.001$.

pocampus of young and mature $\mathrm{Dgcr}^{+/-}$mice. Although we found no difference in SERCA2 levels between $D g c r 8^{+/-}$and WT whole-hippocampal extracts (data not shown), SERCA2 protein levels in synaptosomal preparations from the hippocampus of mature $\operatorname{Dgcr} 8^{+/-}$mice were significantly elevated compared with that in WT littermates $(p<0.001)$ (Fig. $4 A)$. In contrast, this synaptic increase in SERCA2 levels was not present in younger mice, indicating a correlation between SERCA2 elevation and the LTP increase in $\mathrm{Dgcr}^{+/-}$mice (Fig. $4 A$ ).

To test whether this increase in SERCA2 is necessary for enhanced LTP in $D g c r 8^{+/-}$mice, we measured LTP in the presence of the SERCA inhibitor thapsigargin $(4 \mu \mathrm{M})$. SERCA inhibition rescued the LTP increase in $\operatorname{Dgcr} 8^{+/-}$slices to WT levels (Fig. $4 B)$. In the absence of thapsigargin, the fEPSP slope increase measured $6 \mathrm{~h}$ after induction was $\sim 120 \%$ stronger than in the presence of thapsigargin in slices from $\operatorname{Dgcr} 8^{+/-}$mice ( 8 mice: 21 slices vehicle, 21 slices thapsigargin; $p=0.014)$. Furthermore, in 
A

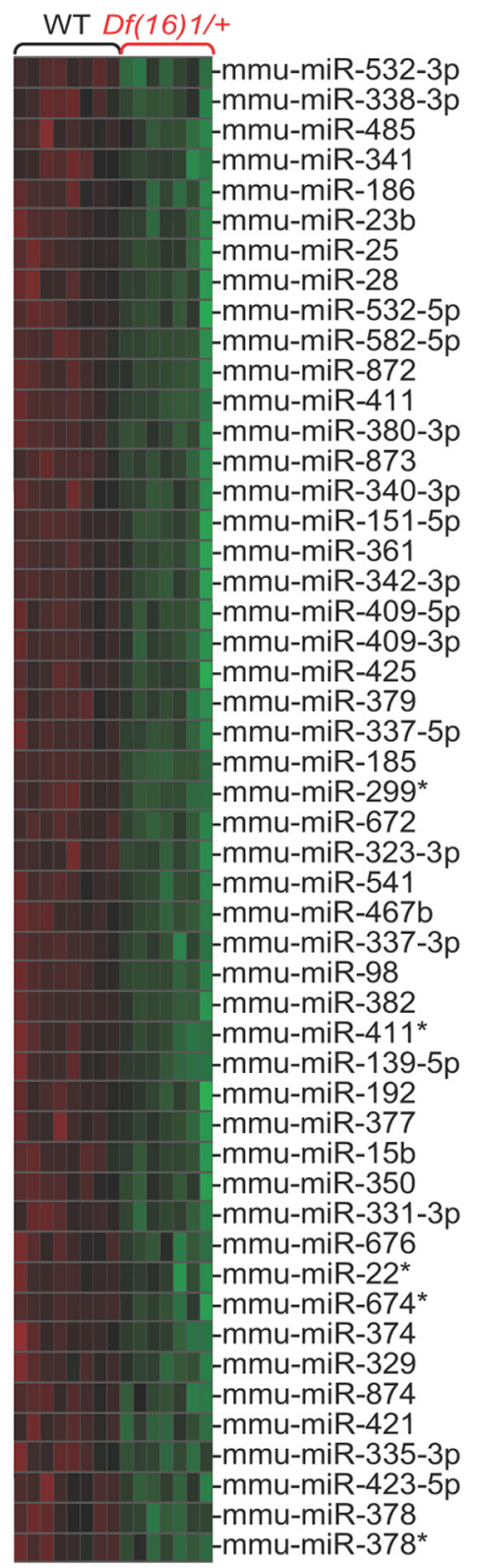

B

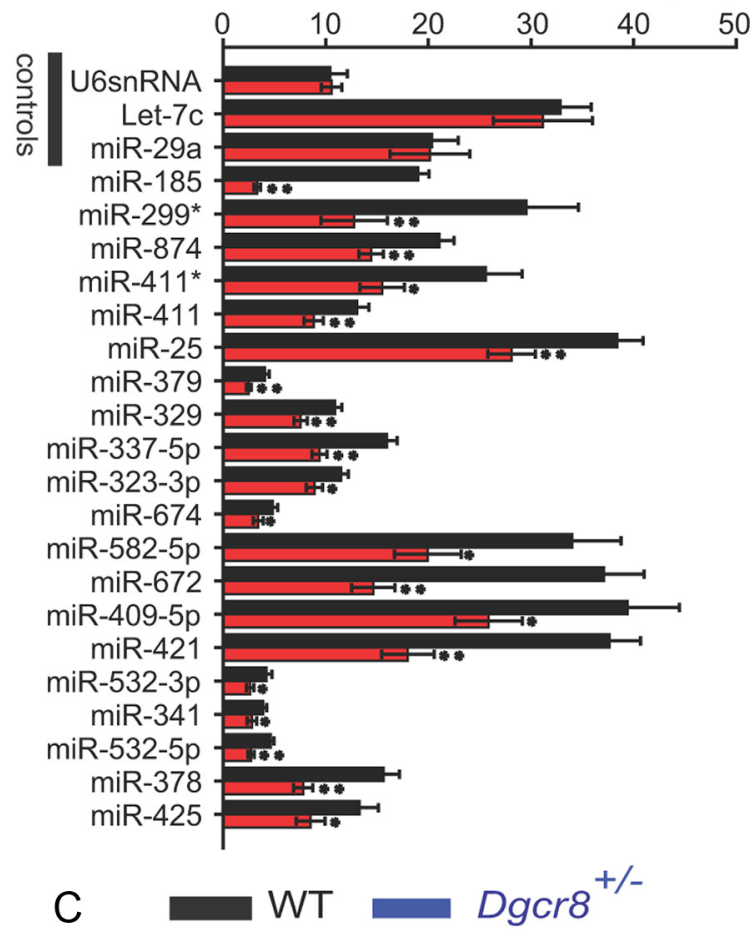

Normalized levels of miRNAs (a.u.)

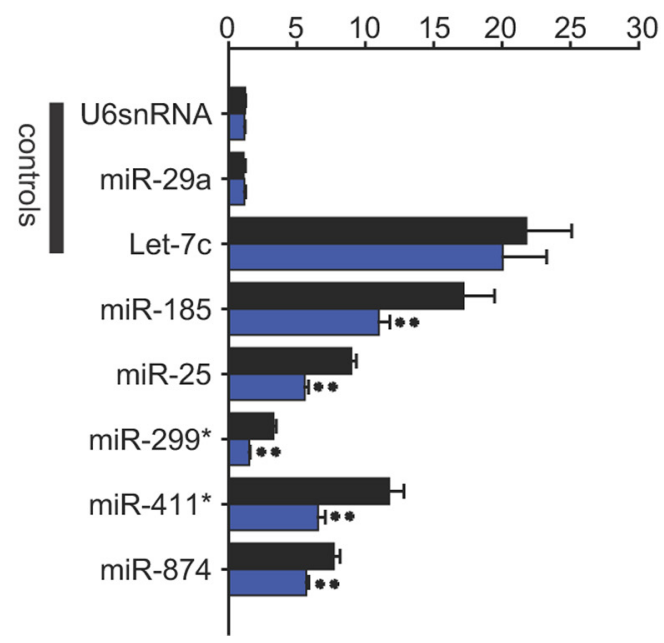

Figure 5. Depletion of miRNAs in the hippocampus of the mature $D f(16) 1 /+$ model of 22q11DS and in $D g c r 8^{+/-}$mice. $A$, Microarray comparison of miRNA expression between 16-week-old Df(16)1/+ mice and WT littermates. $B, C, q P C R$ analyses verified changes in mature miRNA levels in Df(16)1/+ (B) and Dgcr $8^{+/-}(\boldsymbol{C})$ mice compared with WT littermates. ${ }^{*} p<0.05 ;{ }^{* *} p<0.01$.

the presence of thapsigargin, LTP in $\mathrm{Dgcr} 8^{+/-}$mice did not significantly differ from that in WT animals, indicating full rescue $(p=0.854)$. Similar to previously shown results (Earls et al., 2010), thapsigargin did not affect LTP measured in slices from WT littermates ( 8 mice: 24 slices vehicle, 19 slices thapsigargin; $p=0.974)$. These results suggest that SERCA2 is necessary for the observed LTP increase in the mature $\mathrm{Dgcr} 8^{+/-}$hippocampus.

\section{Identification of miRNAs responsible for enhanced LTP in} mouse models of 22q11DS

$D g c r 8$ is an miRNA biogenesis gene, and miRNAs typically act as negative regulators of protein translation. DGCR8 binds to primary
miRNA transcript hairpins and recruits the nuclease DROSHA, which cleaves the hairpins. Further processing produces mature miRNAs that bind to complementary seed sites in the $3^{\prime}$ untranslated regions ( $3^{\prime} \mathrm{UTR}$ ) of target mRNA transcripts and negatively regulate protein translation through recruitment of the RNAinduced silencing complex (Bartel, 2009). We therefore hypothesized that SERCA2 is upregulated in 22q11DS brains due to the age-dependent loss of its regulatory miRNAs. To identify potentially responsible miRNAs, we performed a microarray comparison of hippocampal miRNAs between $D f(16) 1 /+$ and WT littermates (seven mice per genotype) at 16 weeks, the age of onset of the LTP and SERCA2 increase. No miRNAs were elevated, but 50 miRNAs 
Table 1. microRNAs downregulated in Df(16) $1 /+$ mice

\begin{tabular}{|c|c|c|c|c|c|c|c|}
\hline microRNA ID & Rank & $p$ value & Fold change & Chromosome & Start position & End position & Strand \\
\hline mmu-miR-185 & 1 & $6.14 \mathrm{E}-12$ & -3.29 & 16 & 18327494 & 18327558 & - \\
\hline mmu-miR-299* & 2 & $8.57 \mathrm{E}-09$ & -1.88 & 12 & 110948848 & 110948910 & + \\
\hline mmu-miR-337-3p & 3 & $2.07 \mathrm{E}-07$ & -1.88 & 12 & 110823999 & 110824095 & + \\
\hline mmu-miR-411 & 4 & $2.1 \mathrm{E}-06$ & -1.75 & 12 & 110948385 & 110948466 & + \\
\hline mmu-miR-411* & 5 & $1.49 \mathrm{E}-06$ & -1.75 & 12 & 110948385 & 110948466 & + \\
\hline mmu-miR-874 & 6 & $1.12 \mathrm{E}-05$ & -1.71 & 13 & 58124486 & 58124561 & - \\
\hline mmu-miR-374 & 7 & $1.5 \mathrm{E}-05$ & -1.71 & $x$ & 100768399 & 100768493 & - \\
\hline mmu-miR-379 & 8 & $7.36 \mathrm{E}-06$ & -1.68 & 12 & 110947270 & 110947335 & + \\
\hline mmu-miR-337-5p & 9 & 5E-07 & -1.67 & 12 & 110823999 & 110824095 & + \\
\hline mmu-miR-329 & 10 & $1.64 \mathrm{E}-05$ & -1.65 & 12 & 110951691 & 110951787 & + \\
\hline mmu-miR-674* & 11 & $2.18 \mathrm{E}-06$ & -1.63 & 2 & 117010863 & 117010962 & + \\
\hline mmu-miR-323-3p & 12 & $2.17 \mathrm{E}-07$ & -1.60 & 12 & 110950718 & 110950803 & + \\
\hline mmu-miR-582-5p & 13 & $3.21 \mathrm{E}-06$ & -1.57 & 13 & 110114938 & 110115018 & + \\
\hline mmu-miR-98 & 14 & $1.43 \mathrm{E}-07$ & -1.54 & $x$ & 148347757 & 148347864 & + \\
\hline mmu-miR-672 & 15 & $2.29 \mathrm{E}-08$ & -1.54 & $x$ & 101311514 & 101311613 & - \\
\hline mmu-miR-25 & 16 & $1.13 \mathrm{E}-05$ & -1.54 & 5 & 138606549 & 138606632 & - \\
\hline mmu-miR-421 & 17 & $3.44 \mathrm{E}-07$ & -1.53 & $x$ & 100768260 & 100768335 & - \\
\hline mmu-miR-409-5p & 18 & $5.31 \mathrm{E}-06$ & -1.53 & 12 & 110981368 & 110981446 & + \\
\hline mmu-miR-872 & 19 & $2.25 \mathrm{E}-05$ & -1.52 & 4 & 94331848 & 94331928 & + \\
\hline mmu-miR-532-3p & 20 & $2.41 \mathrm{E}-07$ & -1.52 & $x$ & 6825528 & 6825623 & - \\
\hline mmu-miR-425 & 21 & $5.7 \mathrm{E}-06$ & -1.52 & 9 & 108471108 & 108471192 & + \\
\hline mmu-miR-341 & 22 & $2.14 \mathrm{E}-05$ & -1.52 & 12 & 110849710 & 110849805 & + \\
\hline mmu-miR-532-5p & 23 & $2.33 \mathrm{E}-05$ & -1.51 & $x$ & 6825528 & 6825623 & - \\
\hline mmu-miR-378 & 24 & $3.87 \mathrm{E}-06$ & -1.51 & 18 & 61557489 & 61557554 & - \\
\hline mmu-miR-192 & 25 & $5.54 \mathrm{E}-05$ & -1.51 & 19 & 6264844 & 6264932 & + \\
\hline mmu-miR-380-3p & 26 & $1.97 \mathrm{E}-05$ & -1.50 & 12 & 110950013 & 110950073 & + \\
\hline mmu-miR-541 & 27 & $1.13 \mathrm{E}-06$ & -1.49 & 12 & 110980619 & 110980708 & + \\
\hline mmu-miR-873 & 28 & $3.71 \mathrm{E}-06$ & -1.49 & 4 & 36615543 & 36615619 & - \\
\hline mmu-miR-186 & 29 & $2.37 \mathrm{E}-05$ & -1.49 & 3 & 157207243 & 157207313 & + \\
\hline mmu-miR-378* & 30 & $1.11 \mathrm{E}-05$ & -1.48 & 18 & 61557489 & 61557554 & - \\
\hline mmu-miR-361 & 31 & $3.65 \mathrm{E}-06$ & -1.48 & $x$ & 110188433 & 110188502 & - \\
\hline mmu-miR-467b & 32 & $2.52 \mathrm{E}-06$ & -1.47 & 2 & 10402879 & 10402947 & - \\
\hline mmu-miR-151-5p & 33 & $1.58 \mathrm{E}-06$ & -1.47 & 15 & 73085245 & 73085312 & - \\
\hline mmu-miR-28 & 34 & $1.71 \mathrm{E}-05$ & -1.46 & 16 & 24827941 & 24828026 & + \\
\hline mmu-miR-22* & 35 & 5.09E-05 & -1.46 & 11 & 75277218 & 75277312 & + \\
\hline mmu-miR-409-3p & 36 & $1.63 \mathrm{E}-06$ & -1.44 & 12 & 110981368 & 110981446 & + \\
\hline mmu-miR-340-3p & 37 & $2.33 \mathrm{E}-05$ & -1.44 & 11 & 49883204 & 49883301 & + \\
\hline mmu-miR-350 & 38 & $2.98 \mathrm{E}-05$ & -1.43 & 1 & 178702456 & 178702554 & - \\
\hline mmu-miR-331-3p & 39 & $1.17 \mathrm{E}-06$ & -1.43 & 10 & 93426513 & 93426608 & - \\
\hline mmu-miR-423-5p & 40 & $3.47 \mathrm{E}-06$ & -1.42 & 11 & 76891566 & 76891674 & - \\
\hline mmu-miR-382 & 41 & $3.6 \mathrm{E}-07$ & -1.42 & 12 & 110971981 & 110972056 & + \\
\hline mmu-miR-139-5p & 42 & $1.84 \mathrm{E}-06$ & -1.41 & 7 & 108623890 & 108623957 & + \\
\hline mmu-miR-377 & 43 & $7.78 \mathrm{E}-05$ & -1.41 & 12 & 110978720 & 110978787 & + \\
\hline mmu-miR-342-3p & 44 & $1.62 \mathrm{E}-06$ & -1.41 & 12 & 109896830 & 109896928 & + \\
\hline mmu-miR-15b & 45 & $2.31 \mathrm{E}-05$ & -1.37 & 3 & 68813694 & 68813757 & + \\
\hline mmu-miR-338-3p & 46 & $4.29 \mathrm{E}-05$ & -1.36 & 11 & 119876079 & 119876176 & - \\
\hline mmu-miR-335-3p & 47 & $1.58 \mathrm{E}-05$ & -1.35 & 6 & 30691299 & 30691396 & + \\
\hline mmu-miR-485 & 48 & $6.64 \mathrm{E}-05$ & -1.32 & 12 & 110973112 & 110973184 & + \\
\hline mmu-miR-23b & 49 & $5.84 \mathrm{E}-06$ & -1.29 & 13 & 63401792 & 63401865 & + \\
\hline mmu-miR-676 & 50 & $1.23 \mathrm{E}-05$ & -1.28 & $x$ & 97576436 & 975765424 & + \\
\hline
\end{tabular}

were significantly reduced at this stage in the $D f(16) 1 /+$ mutants (Fig. 5A; Table 1). We verified the depletion of mature forms of 20 of these miRNAs in $D f(16) 1 /+$ hippocampus by qPCR (Fig. $5 B$ ). For a subset of these miRNAs, we also verified their depletion in the $D g c r 8^{+/-}$hippocampus at 16 weeks, and found that the same miRNAs were depleted in both animal models (Fig. 5C).

miRNAs affect their target mRNAs by binding to complementary seed sites within the 3'UTR and recruiting the RNA-induced silencing complex to the transcript to prevent translation (Ambros, 2004). We therefore used miRNA target prediction algorithms to narrow down the list of candidate miRNAs found from the microarray to only those predicted to target the Serca2 transcript. Using the algorithms miRBase (Enright et al., 2003), TargetScan (Lewis et al.,
2005), DIANA-microT v3.0 (Kiriakidou et al., 2004), and miRDB (Wang and El Naqa, 2008), we identified potential seed sites for miRNAs within the 3'UTR of the murine Serca2 transcript (Table 2). Of the miRNAs depleted in 22q11DS mice, three were predicted to target the SERCA2 3'UTR: miR-25, -98, and -185. Depletion of mature forms of miR-25 and miR-185 in $D f(16) 1 /+$ mice was verified by qPCR (Fig. 5B). However, depletion of mature miR-98 in $D f(16) 1 /+$ mice could not be verified due to the AT-rich nature of this miRNA. We nonetheless hypothesize that the depletion of any of these miRNAs contributes to SERCA2 upregulation and abnormal LTP in 22q11DS mouse models. A diagram of the murine SERCA2 3 'UTR with the locations of predicted seed sites for these three miRNAs is shown in Figure $6 \mathrm{~A}$. 
Table 2. microRNAs predicted by four algorithms to bind the $3^{\prime}$ UTR of murine Serca2

\begin{tabular}{|c|c|c|c|c|c|c|c|}
\hline \multicolumn{2}{|l|}{ miRBase } & \multicolumn{2}{|l|}{ TargetScan } & \multicolumn{2}{|l|}{ miRDB } & \multicolumn{2}{|l|}{ microT v3.0 } \\
\hline microRNA (mmu-miR) & Score & microRNA (mmu-miR) & Score & microRNA (mmu-miR) & Score & microRNA (mmu-miR) & Score \\
\hline $369-3 p$ & 298 & 363 & -0.39 & 4661 & 99 & 92 & 27.53 \\
\hline 1190 & 285 & 32 & -0.38 & 544 & 90 & $30 a-5 p$ & 27.21 \\
\hline $25^{*}$ & 164 & $92 b$ & -0.38 & $654-3 p$ & 86 & $30 \mathrm{e}$ & 27.1 \\
\hline $466 \mathrm{~g}$ & 162 & 367 & -0.38 & 805 & 83 & $30 d$ & 27.06 \\
\hline 544 & 162 & $25^{*}$ & -0.38 & $764-3 p$ & 82 & $30 c$ & 26.94 \\
\hline 363 & 159 & $92 \mathrm{a}$ & -0.38 & 367 & 78 & $30 b$ & 26.93 \\
\hline $450 a-3 p$ & 159 & 544 & -0.42 & $25^{*}$ & 76 & let-7b & 23.67 \\
\hline $764-3 p$ & 157 & 298 & -0.31 & $151-3 p$ & 75 & let-7c & 23.48 \\
\hline $142-3 p$ & 155 & 804 & -0.13 & 363 & 73 & let-7g & 23.34 \\
\hline $574-3 p$ & 155 & $509-3 p$ & -0.17 & $92 \mathrm{a}$ & 73 & $98^{*}$ & 23.29 \\
\hline 1198 & 146 & 470 & -0.37 & $92 b$ & 72 & let-7i & 23.29 \\
\hline $139-5 p$ & 152 & $450 b-5 p$ & -0.38 & 32 & 71 & let-7f & 23.29 \\
\hline $135 a$ & 151 & 668 & -0.13 & 679 & 67 & let-7a & 23.28 \\
\hline $135 b$ & 151 & 4661 & -0.4 & 568 & 66 & 32 & 22.8 \\
\hline 452 & 151 & $764-3 p$ & -0.4 & $181 \mathrm{~b}$ & 63 & let-7e & 17.44 \\
\hline $654-3 p$ & 150 & $369-3 p$ & -0.22 & $181 d$ & 61 & $148 \mathrm{~b}$ & 14.78 \\
\hline 367 & 149 & $466 \mathrm{~g}$ & -0.43 & 496 & 61 & 152 & 14.6 \\
\hline 4661 & 149 & $654-3 p$ & -0.24 & $181 c$ & 60 & $148 a$ & 13.56 \\
\hline 33 & 148 & 1198 & -0.11 & $181 a$ & 60 & 363 & 13.43 \\
\hline $466 f-3 p$ & 148 & $450 a-3 p$ & -0.18 & $509-5 p$ & 60 & $200 \mathrm{a}$ & 12.71 \\
\hline 539 & 148 & $126-5 p$ & -0.18 & $466 \mathrm{~g}$ & 59 & 141 & 12.71 \\
\hline 707 & 148 & 135 & -0.16 & $142-3 p$ & 58 & $181 d$ & 11.77 \\
\hline $92 b$ & 148 & 425 & -0.08 & $376 a$ & 58 & $181 \mathrm{~b}$ & 11.72 \\
\hline 128 & 147 & 489 & -0.07 & $338-5 p$ & 54 & 381 & 10.45 \\
\hline $376 a$ & 147 & $142-3 p$ & -0.44 & $466 f-3 p$ & 53 & 301 & 9.67 \\
\hline $323-3 p$ & 146 & 763 & -0.2 & 1944 & 51 & 721 & 9.58 \\
\hline $345-3 p$ & 146 & $345-3 p$ & -0.16 & & & 182 & 9.58 \\
\hline $501-3 p$ & 146 & $19 b$ & -0.12 & & & $301 \mathrm{~b}$ & 9.56 \\
\hline $669 d$ & 146 & 19a & -0.12 & & & 712 & 9.46 \\
\hline $181 a$ & 145 & $376 a$ & -0.23 & & & $130 \mathrm{~b}$ & 9.41 \\
\hline 298 & 145 & 762 & -0.19 & & & $130 \mathrm{a}$ & 9.38 \\
\hline 804 & 145 & 128 & -0.21 & & & $200 \mathrm{c}$ & 8.91 \\
\hline $380-5 p$ & 144 & 882 & -0.09 & & & $200 \mathrm{~b}$ & 8.91 \\
\hline $876-3 p$ & 144 & $185^{*}$ & -0.09 & & & 367 & 8.9 \\
\hline 879 & 144 & 539 & -0.2 & & & $25^{*}$ & 8.17 \\
\hline 195 & 143 & $340-5 p$ & -0.17 & & & 707 & 8.05 \\
\hline $291 b-3 p$ & 143 & $338-5 p$ & -0.17 & & & 429 & 7.8 \\
\hline $669 \mathrm{k}$ & 143 & $770-5 p$ & -0.19 & & & & \\
\hline $92 a$ & 143 & $139-5 p$ & -0.18 & & & & \\
\hline $126-5 p$ & 142 & $487 \mathrm{~b}$ & -0.1 & & & & \\
\hline $301 a$ & 142 & 707 & -0.13 & & & & \\
\hline 500 & 142 & 377 & -0.12 & & & & \\
\hline 669 h-3p & 142 & 326 & -0.1 & & & & \\
\hline $181 \mathrm{~b}$ & 141 & 330 & -0.1 & & & & \\
\hline 763 & 141 & 761 & -0.15 & & & & \\
\hline 105 & 140 & 214 & -0.15 & & & & \\
\hline 154 & 140 & 379 & -0.05 & & & & \\
\hline 32 & 140 & $466 f-3 p$ & -0.24 & & & & \\
\hline 377 & 140 & 720 & -0.06 & & & & \\
\hline $450 b-5 p$ & 140 & 139 & -0.11 & & & & \\
\hline 470 & 140 & $582-5 p$ & -0.1 & & & & \\
\hline 762 & 140 & & & & & & \\
\hline
\end{tabular}

*microRNAs depleted in the Df(16)1/+ mouse model of 22q11DS (see Table 1).

Rescue of the LTP increase in $\mathrm{Dgcr}^{+/-}$mice by presynaptic restoration of miR-25 or miR-185

To test whether depletion of the miRNAs of interest is required for the observed LTP increase in 22q11DS models, we attempted to restore miR-25 or miR-185 to hippocampal neurons of $\mathrm{Dgcr} 8^{+/-}$ mice to rescue the LTP phenotype. To do this, we generated recombinant AAVs that encode GFP just upstream of either miR-25 or miR-185 under the control of the neuron-specific Synapsin promoter to infect adult neurons in vivo according to a previously described method (Christensen et al., 2010). Because the increase in LTP measured at CA3-CA1 synapses in mature Df(16)1/+ hippocampus is caused by presynaptic abnormalities (Earls et al., 2010), we injected virus into the CA3 region of the hippocampus in vivo. Injections were performed at 10 weeks of age, before the onset of LTP abnormalities. We injected AAV expressing a given miRNA into one hemisphere and an empty AAV (expressing only GFP) into the contralateral hemisphere as a control. We then measured LTP in both miRNA-injected and control-injected hippocampi at 16 weeks. AAV-driven GFP expression was robust in presynaptic CA3 neurons, but GFP was absent from postsynaptic CA1 neurons (Fig. 6B), suggesting successful targeting of presynaptic CA3 neurons. Using double staining with the nuclear fluorescent dye DAPI (a measure of overall number of cells) and GFP (a measure of infected neurons) we estimated the infection rate of neurons by AAVs in the pyramidal 
layer of the CA3 area to be $\sim 88 \%$ ( 10 slices) (Fig. 6B). Using qPCR, we verified that injection of AAV-miRNAs at 10 weeks of age resulted in elevation of respective miRNAs at 16 weeks (Fig. 6C). AAV-driven overexpression of these miRNAs appeared modest, mainly because we measured miRNA levels throughout the hippocampus after injecting our rescue viruses only in the CA3 region. Therefore, the levels of miRNAs measured in these experiments are an underestimation.

Further, to verify that miR-25 and miR-185 target the Serca2 transcript and thus affect SERCA2 protein levels, we injected these viruses into the $\mathrm{CA} 3$ region of 4 WT animals at 10 weeks of age. We injected GFP-only vector on the contralateral side as a control. At 16 weeks of age, we harvested hippocampi and used quantitative Western blotting to compare SERCA2 levels. As shown in Figure 6D, SERCA2 decreased with overexpression of either miR-25 or miR-185. As with the qPCR results, this is an underestimation of the effect of these miRNAs on SERCA2, because the injection was specific to CA3 while Western blotting was performed in the entire hippocampus.

Importantly, presynaptic expression of either miR-25 or miR-185 was sufficient to rescue the increased LTP in $\operatorname{Dgcr} 8^{+/-}$hippocampus (Fig. 6E). These results indicate that presynaptic depletion of SERCA2-targeting miRNAs causes the LTP increase in 22q11DS mouse models, and restoration of any of these miRNAs is sufficient to rescue this abnormality in synaptic plasticity.

\section{Elevation of SERCA2 in postmortem brain tissue from patients with schizophrenia}

In this work and previously, we showed that SERCA2 is elevated in the hippocampus of the $D f(16) 1 /+$ mouse model of 22q11DS (Earls et al., 2010). However, the hippocampus is clearly not the only brain region involved in psychiatric disease associated with the deletion. To determine the specificity of this upregulation, we tested SERCA2 levels in various tissues of $D f(16) 1 /+$ mice. SERCA2 was elevated in all tested brain regions of $D f(16) 1 /+$ mice, including the cortex $(125.2 \pm 5.6 \%$ of the WT level, $p=$ $0.012 ; 4$ mice per genotype) and cerebellum (124.6 $\pm 7.5 \%$ of the WT level, $p=0.048 ; 4$ mice per genotype), but not in non-neural tissues such as liver $(96.9 \pm 4.7 \%$ of the WT level, $p=0.689 ; 3-4$ mice per genotype). These findings indicate that changes in SERCA2 expression are brain specific and found throughout the brain.

Because the elevation of SERCA2 has serious consequences for neural function, we questioned whether the molecular findings in these 22q11DS mouse models might translate to human disease. We compared SERCA2 levels in postmortem tissue samples from the hippocampus and prefrontal cortex of patients with schizophrenia and unaffected controls. This comparison revealed a sig-
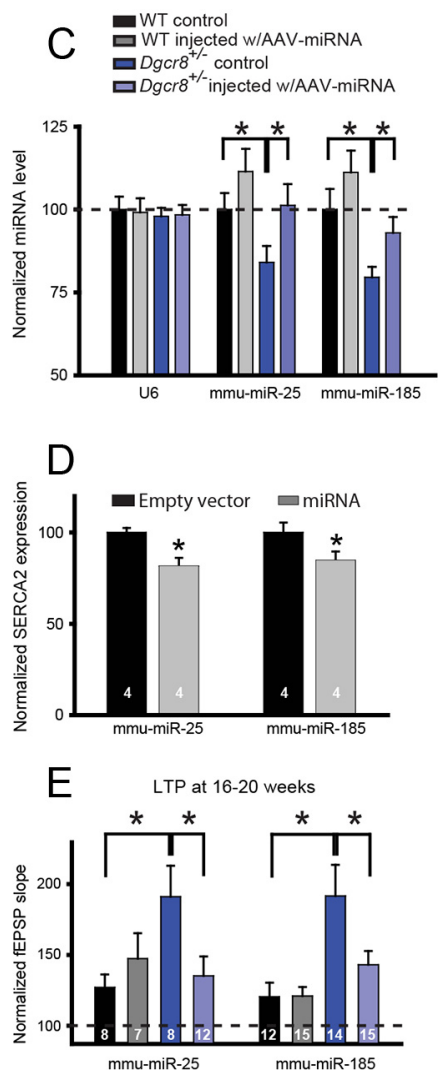

Figure 6. Restoring depleted miRNAs rescues the LTP increase in mature Dgcr $8^{+/}$mice. $A$, Diagram of the mouse Serca $2 b$ 3'UTR (NR_027838) with miRNA seed sites indicated. $\boldsymbol{B}$, Viral strategy to overexpress miRNAs in vivo. AAV constructs encoding GFP a chimeric miRNA hairpin under control of the Synapsin promoter were used (top). Representative fluorescence image of the

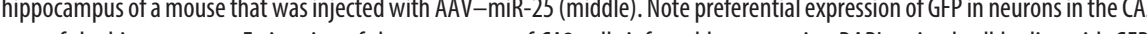
the percentage of CA3 cells infected by comparing DAPI-stained cell bodies with GFPempty ver indicated inside the bars. $E$, LTP in mature $D g c r 8^{+/}$- mice and WT littermates with or without overexpression of miR-25 or miR-185 in the CA3 area of the hippocampus. Numbers of slices are indicated inside the bars. ${ }^{*} p<0.05$.

nificant increase in SERCA2 levels in both brain regions of patients with schizophrenia (Fig. 7A). Given the severe phenotype associated with SERCA2 elevation in mouse neurons, this finding suggests that elevation in SERCA2 protein may contribute to neural deficits in schizophrenia. The seed sites for hsamiR-25, hsa-miR-98, and hsa-miR-185 are conserved in the 3'UTR of human Serca2B (Fig. 7B), suggesting that modulation by these miRNAs is a potential mechanism for the observed SERCA2 protein overexpression in schizophrenia.

\section{Discussion}

Schizophrenia is a devastating disease that severely affects cognitive function and currently has no cure. Here we report three new findings that expand our understanding of 22q11DS, which poses a major risk for schizophrenia. First, we showed that 22q11DS and schizophrenia are associated with elevated SERCA2 levels in the brain. SERCA2 was elevated in the brains of mouse models and patients with schizophrenia. Given previous work showing that elevated SERCA2 substantially affects synaptic function (Earls et al., 2010), altered SERCA2 levels may be involved in schizophrenia symptoms. Second, we determined that Dgcr8, a miRNA-processing gene, is the $22 \mathrm{q} 11$ gene responsible for SERCA2 elevation in the mouse. Third, we showed that the LTP increase in mice is caused by the loss of miRNAs that target 
A

$$
\text { Unaffected controls }
$$
Prefrontal cortex

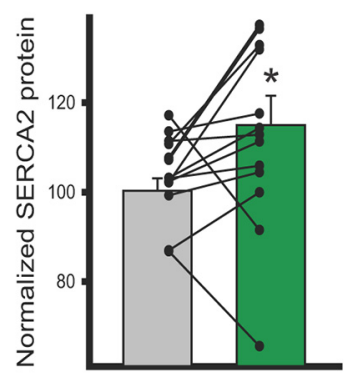

$\mathrm{B}$

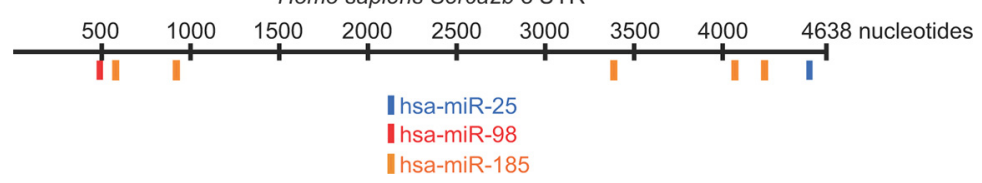

Figure 7. SERCA2 is elevated in postmortem brains of patients with schizophrenia. $A$, Quantitative Western blotting of SERCA2 levels in postmortem brain extracts from the prefrontal cortex (left) and hippocampus (right) of unaffected controls (gray) and patients with schizophrenia (green). Age-, sex-, and race-matched (prefrontal cortex) or age- and sex-matched (hippocampus) samples are represented in line graphs. Average data ( \pm SEM) for all available samples (prefrontal cortex: 22 unaffected and 17 schizophrenia; hippocampus: 6 unaffected and 5 schizophrenia; run in triplicate) are shown in bar graphs. $\boldsymbol{B}$, Diagram of the 3' UTR of human SERCA2B (NM_170665) with conserved seed sites for hsa-miR-25, hsa-miR-98, and hsa-miR-185. * $p<0.05$.

SERCA2 (miR-25 and miR-185). This finding was verified by the fact that restoration of depleted miRNAs rescues LTP abnormalities in $\mathrm{Dgcr} 8^{+/-}$mice. Furthermore, since presynaptic injection of miRNAs was sufficient to rescue the LTP deficit, this validates previous findings that functional alterations at this synapse are presynaptic in nature. Our model of the pathway for miRNA modulation of SERCA2 and synaptic plasticity (Fig. 8) outlines potential novel targets for therapeutic approaches to treat cognitive deficits in 22q11DS and schizophrenia.

The hemizygous loss of a group of genes causes 22q11DS, which is characterized by physical and cognitive abnormalities. Identifying the genes responsible for each category of 22q11DS symptoms is crucial for understanding the pathogenesis of the disease. Past work has shown that haploinsufficiency of the 22q11.2 gene Tbx1 causes some physical abnormalities in 22q11DS (Jerome and Papaioannou, 2001; Lindsay et al., 2001; Merscher et al., 2001). However, the genes involved in the cognitive deficits have remained elusive, perhaps because behavioral assays reveal only mild deficits in 22q11DS mouse models and therefore are not amenable to nonbiased screening. In contrast, the substantial age-dependent increase in LTP observed in $D f(16) 1 /+$ mice provides a robust assay for identifying culprit genes that contribute to cognitive symptoms in 22q11DS (Earls et al., 2010).

Using $D f(16) 2 /+$ and Znf74l-Ctp/+ subdeletion mice, we narrowed the causal region of age-dependent LTP increase to the Trxr2-Dgcr6 genomic region. Further screening of multiple strains deficient in individual genes within this region revealed that hemizygous deletion of $D g c r 8$ recapitulates the $D f(16) 2 /+$ phenotype. The magnitude of the LTP increase was comparable between mature $D f(16) 2 /+$ and $D g c r 8^{+/-}$mice, suggesting that $D g c r 8$ is the sole contributor to the $D f(16) 2 /+$ phenotype.

Because DGCR8 controls miRNA biosynthesis, we hypothesized that neural deficits observed in our 22q11DS mouse models are caused by the age-dependent depletion of miRNAs. The involvement of miRNAs in age-related alterations in plasticity is an attractive model for several reasons. First, miRNAs are developmentally expressed (Miska et al., 2004), and the loss of miRNAs during a critical period may explain the age dependence of this phenotype. Second, we previously showed that SERCA2 is upregulated at the protein level but not at the transcript level in $D f(16) 1 /+$ mice (Earls et al., 2010). miRNAs typically affect protein levels of their targets independently of transcript levels, which is consistent with the modulation of SERCA2 observed in our mouse model. Finally, although the changes seen in SERCA2 levels were significant, they were modest. This is also consistent with modulation by miRNAs, which fine-tune protein expression levels rather than result in robust expression changes (Baek et al., 2008).

Using microarray analysis, we identified miRNAs that were depleted in $D f(16) 1 /+$ mice at the age of the LTP phenotype onset. Only seven (14\%) were common with those identified in a previous microarray analysis of young (8- to 10-week-old) 22q11DS mouse models (Stark et al., 2008). This speaks to the dynamic nature of miRNA expression during development. Individual primary miRNA transcripts may be sensitive to $\operatorname{Dgcr} 8$ loss at different developmental stages. We identified three miRNAs (miR-25, -98 , and -185 ) that are predicted to target the $3^{\prime}$ UTR of Serca2. We confirmed depletion of miR-25 and miR-185 in mouse models of 22q11DS by qPCR. We were unable to validate depletion of miR-98 due to the AT-rich nature of this miRNA. However, all miRNAs tested by qPCR produced similar results to the microarray, suggesting that the microarray list, in general, is valid and that miR-98 is a potential contributor to the phenotypes discussed here. Restoring either miR-25 or miR-185 levels in presynaptic neurons rescued the LTP phenotype in $\mathrm{Dgcr}^{+/-}$mice, indicating that reintroducing a single SERCA2-targeting miRNA in presynaptic neurons is sufficient to return LTP to its normal level. Previous work has shown that miR-25, miR-98, and miR185 are present or enriched in synapses (Lugli et al., 2008; Smalheiser, 2008; Siegel et al., 2009). This may explain why the increase in SERCA2 was detected in synapses in the mature $\operatorname{Dgcr} 8^{+/-}$hippocampus.

miRNA-185 may be particularly important for the pathology of 22 q11DS, because the genomic region encoding miR-185 is contained within an intron of the 22q11.2 gene T10. Here, we show that miR-185 is also modulated by $D g c r 8$ loss, as miR-185 is significantly reduced in $\mathrm{Dgcr} 8^{+/-}$mice. Thus, in 22q11DS, miR185 is downregulated at both the genomic and transcript levels. Additionally, the 3'UTR of the human SERCA2 transcript contains four predicted seed sites for miR-185 not found in the mouse transcript. Together, these findings suggest that miR-185 regulates cognitive and psychiatric symptoms of patients with 22q11DS.

Because 22q11DS is responsible for only a subset of schizophrenia cases (International Schizophrenia Consortium, 2008; Stefansson et al., 2008; Xu et al., 2008), we sought to determine how the above pathway is affected in schizophrenia that is not associated with the deletion. Surprisingly, we found that the in- 
crease in SERCA2 levels shown in mouse models of 22q11DS is also present in patients with schizophrenia. Because miRNA loss leads to SERCA2 elevation in mouse models of 22q11DS, we hypothesized that miRNA regulation of SERCA2 translation could also mediate the observed elevation of SERCA2 protein in patients with schizophrenia. Several groups have attempted to quantify miRNA levels in postmortem schizophrenia brains, but the results have shown little overlap (Perkins et al., 2007; Beveridge et al., 2010; Kim et al., 2010; Moreau et al., 2011). These differences are most likely due to different sampling of miRNAs in various studies, but variations in postmortem intervals and tissue-handling methods may also contribute to these differences. As we were unable to obtain quality RNA from the postmortem samples in this study, we could not reliably measure miRNA levels. Future studies will seek to determine the correlation between the levels of miRNAs and SERCA2 in human brain samples collected after shorter postmortem intervals.

SERCA2 upregulation in patients with schizophrenia may also be caused by miRNAindependent mechanisms. The SERCA2 pump, as a part of the $\mathrm{Ca}^{2+}$ homeostasis machinery, is very tightly regulated (Vandecaetsbeek et al., 2011). This control is essential, especially in presynaptic terminals of central synapses, where the relationship between cytoplasmic $\mathrm{Ca}^{2+}$ concentration and neurotransmitter release is described by a fourth-power relationship (Mintz et al., 1995; Borst and Sakmann, 1996). Thus, slight changes in SERCA2 levels can have sizable consequences on presynaptic function, synaptic plasticity, and cognition. SERCA2 upregulation in the 22q11DS model mice causes an aberrant $\mathrm{Ca}^{2+}$ increase in the presynaptic terminals, which in turn leads to abnormally enhanced LTP (Earls et al., 2010). Similar changes in plasticity may occur in patients with schizophrenia who have increased SERCA2 levels. Although miRNA modulation may be one way to achieve this, SERCA2 is also regulated by other mechanisms (Vandecaetsbeek et al., 2011). Future studies will seek to determine which of these mechanisms contributes to SERCA2 misregulation in the brains of patients with schizophrenia. Regardless of how SERCA2 changes, our results indicate that SERCA2 upregulation at synapses may be a pathogenic mechanism of schizophrenia.

In this study, we identified the contribution of $\operatorname{Dgcr} 8$ to the agedependent plasticity deficits observed in the 22q11DS mouse model. The magnitude of LTP increase measured in $\mathrm{Dgcr}^{+/-}$and $D f(16) 2 /+$ mice was smaller than that observed in $D f(16) 1 /+$ mice (Earls et al., 2010). Furthermore, hippocampus-dependent spatial learning and memory measured in Morris water maze tasks was normal in ma-

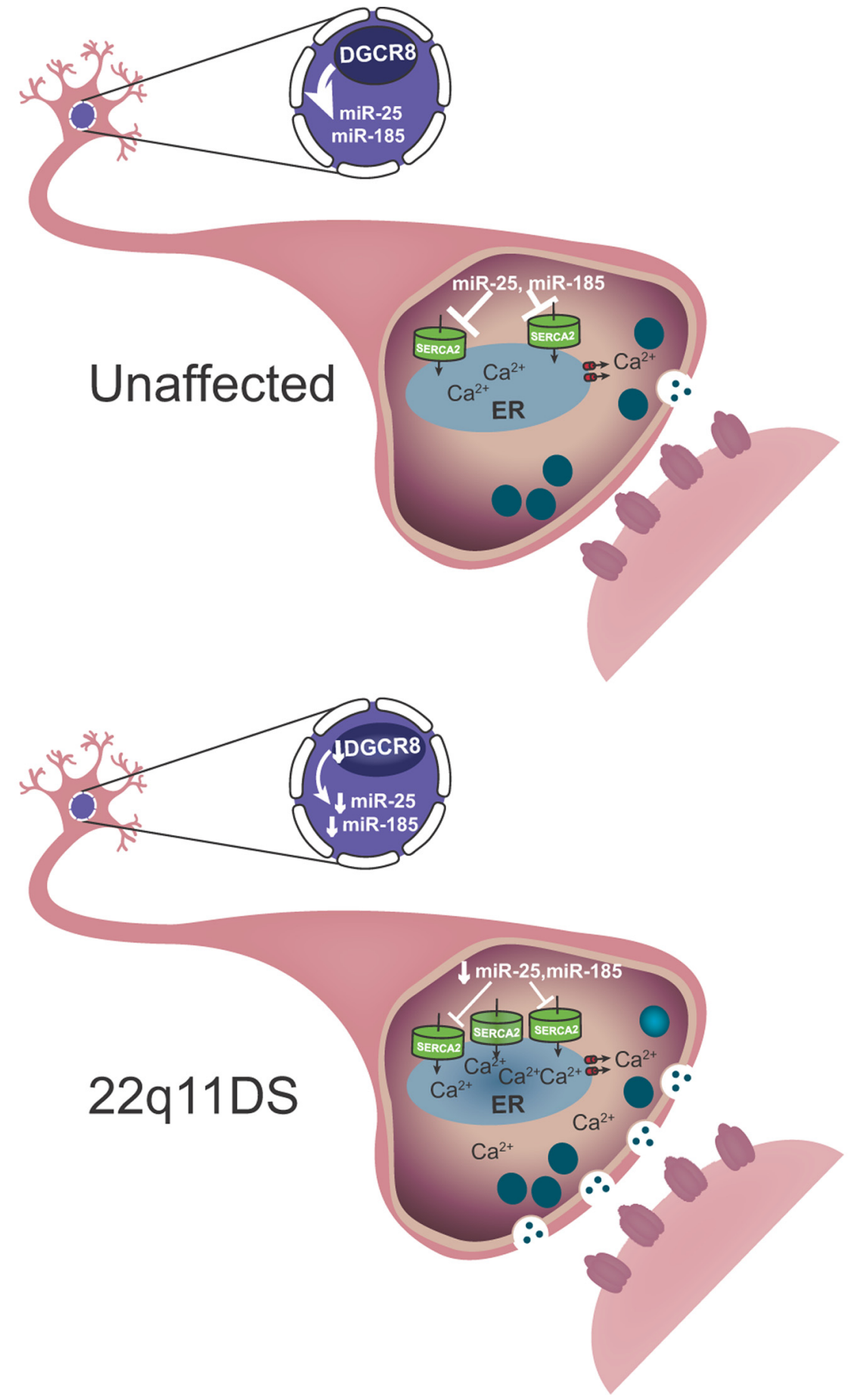

Figure 8. Model of SERCA2-dependent mechanism of neural dysfunction in 22q11DS and schizophrenia. DGCR8 normally produces miRNAs that negatively control the expression of SERCA2 at synapses with age (top). In 22q11DS, Dgcr8 and miR-185 haploinsufficiency releases the regulation of SERCA2. Consequent SERCA2 upregulation leads to elevated ER $\mathrm{Ca}^{2+}$ and enhanced neurotransmitter release (bottom). 
Since the original description of schizophrenia, the disease's causative molecular mechanisms have remained elusive. Schizophrenia has a complex etiology, affects multiple brain systems, and may arise from different molecular insults. Presynaptic perturbation of $\mathrm{Ca}^{2+}$ signaling due to SERCA2 upregulation contributes to the cognitive deficits that are central to this disease. The finding that SERCA2 is upregulated in the human brain with schizophrenia provides a mechanistic link between 22q11DS and schizophrenia. Here we identified miR-25 and miR-185 as regulators of SERCA2. These miRNAs are depleted in 22q11DS due to Dgcr8 deficiency. Restoration of these miRNAs in presynaptic neurons rescued synaptic plasticity deficits in Dgcr8-deficient mice. These findings suggest that progressive miRNA-dependent SERCA2 upregulation at central synapses is a pathogenic mechanism of 22q11DS.

\section{References}

Ambros V (2004) The functions of animal microRNAs. Nature 431:350-355.

Baek D, Villén J, Shin C, Camargo FD, Gygi SP, Bartel DP (2008) The impact of microRNAs on protein output. Nature 455:64-71.

Bartel DP (2009) MicroRNAs: target recognition and regulatory functions. Cell 136:215-233.

Bassett AS, Chow EW, Husted J, Weksberg R, Caluseriu O, Webb GD, Gatzoulis MA (2005) Clinical features of 78 adults with 22q11 deletion syndrome. Am J Med Genet A 138:307-313.

Beveridge NJ, Gardiner E, Carroll AP, Tooney PA, Cairns MJ (2010) Schizophrenia is associated with an increase in cortical microRNA biogenesis. Mol Psychiatry 15:1176-1189.

Borst JG, Sakmann B (1996) Calcium influx and transmitter release in a fast CNS synapse. Nature 383:431-434.

Burn J, Takao A, Wilson D, Cross I, Momma K, Wadey R, Scambler P, Goodship J (1993) Conotruncal anomaly face syndrome is associated with a deletion within chromosome 22q11. J Med Genet 30:822-824.

Chow EW, Watson M, Young DA, Bassett AS (2006) Neurocognitive profile in 22q11 deletion syndrome and schizophrenia. Schizophr Res 87:270-278.

Christensen M, Larsen LA, Kauppinen S, Schratt G (2010) Recombinant adeno-associated virus-mediated microRNA delivery into the postnatal mouse brain reveals a role for miR-134 in dendritogenesis in vivo. Front Neural Circuits 3:16.

Earls LR, Bayazitov IT, Fricke RG, Berry RB, Illingworth E, Mittleman G, Zakharenko SS (2010) Dysregulation of presynaptic calcium and synaptic plasticity in a mouse model of 22q11 deletion syndrome. J Neurosci 30:15843-15855.

Enright AJ, John B, Gaul U, Tuschl T, Sander C, Marks DS (2003) MicroRNA targets in Drosophila. Genome Biol 5:R1.

Gogos JA, Morgan M, Luine V, Santha M, Ogawa S, Pfaff D, Karayiorgou M (1998) Catechol-O-methyltransferase-deficient mice exhibit sexually dimorphic changes in catecholamine levels and behavior. Proc Natl Acad Sci U S A 95:9991-9996.

Gogos JA, Santha M, Takacs Z, Beck KD, Luine V, Lucas LR, Nadler JV, Karayiorgou M (1999) The gene encoding proline dehydrogenase modulates sensorimotor gating in mice. Nat Genet 21:434-439.

Gold JM (2004) Cognitive deficits as treatment targets in schizophrenia. Schizophr Res 72:21-28.

Gray EG, Whittaker VP (1962) The isolation of nerve endings from brain: an electron-microscopic study of cell fragments derived by homogenization and centrifugation. J Anat 96:79-88.

Green MF (1996) What are the functional consequences of neurocognitive deficits in schizophrenia? Am J Psychiatry 153:321-330.

Green MF, Kern RS, Braff DL, Mintz J (2000) Neurocognitive deficits and functional outcome in schizophrenia: are we measuring the "right stuff"? Schizophr Bull 26:119-136.

Heckers S, Rauch SL, Goff D, Savage CR, Schacter DL, Fischman AJ, Alpert NM (1998) Impaired recruitment of the hippocampus during conscious recollection in schizophrenia. Nat Neurosci 1:318-323.

International Schizophrenia Consortium (2008) Rare chromosomal deletions and duplications increase risk of schizophrenia. Nature 455:237-241.
Jerome LA, Papaioannou VE (2001) DiGeorge syndrome phenotype in mice mutant for the T-box gene, Tbx1. Nat Genet 27:286-291.

Kim AH, Reimers M, Maher B, Williamson V, McMichael O, McClay JL, van den Oord EJ, Riley BP, Kendler KS, Vladimirov VI (2010) MicroRNA expression profiling in the prefrontal cortex of individuals affected with schizophrenia and bipolar disorders. Schizophr Res 124:183-191.

Kim JE, Liu BP, Park JH, Strittmatter SM (2004) Nogo-66 receptor prevents raphespinal and rubrospinal axon regeneration and limits functional recovery from spinal cord injury. Neuron 44:439-451.

Kimber WL, Hsieh P, Hirotsune S, Yuva-Paylor L, Sutherland HF, Chen A, Ruiz-Lozano P, Hoogstraten-Miller SL, Chien KR, Paylor R, Scambler PJ, Wynshaw-Boris A (1999) Deletion of $150 \mathrm{~kb}$ in the minimal DiGeorge/ velocardiofacial syndrome critical region in mouse. Hum Mol Genet 8:2229-2237.

Kiriakidou M, Nelson PT, Kouranov A, Fitziev P, Bouyioukos C, Mourelatos Z, Hatzigeorgiou A (2004) A combined computational-experimental approach predicts human microRNA targets. Genes Dev 18:1165-1178.

Lewis BP, Burge CB, Bartel DP (2005) Conserved seed pairing, often flanked by adenosines, indicates that thousands of human genes are microRNA targets. Cell 120:15-20.

Lindsay EA, Botta A, Jurecic V, Carattini-Rivera S, Cheah YC, Rosenblatt HM, Bradley A, Baldini A (1999) Congenital heart disease in mice deficient for the DiGeorge syndrome region. Nature 401:379-383.

Lindsay EA, Vitelli F, Su H, Morishima M, Huynh T, Pramparo T, Jurecic V, Ogunrinu G, Sutherland HF, Scambler PJ, Bradley A, Baldini A (2001) Tbx1 haploinsufficieny in the DiGeorge syndrome region causes aortic arch defects in mice. Nature 410:97-101.

Lugli G, Torvik VI, Larson J, Smalheiser NR (2008) Expression of microRNAs and their precursors in synaptic fractions of adult mouse forebrain. J Neurochem 106:650-661.

Martin SJ, Grimwood PD, Morris RG (2000) Synaptic plasticity and memory: an evaluation of the hypothesis. Annu Rev Neurosci 23:649-711.

Merscher S, et al (2001) TBX1 is responsible for cardiovascular defects in velo-cardio-facial/DiGeorge syndrome. Cell 104:619-629.

Milner B, Squire LR, Kandel ER (1998) Cognitive neuroscience and the study of memory. Neuron 20:445-468.

Mintz IM, Sabatini BL, Regehr WG (1995) Calcium control of transmitter release at a cerebellar synapse. Neuron 15:675-688.

Miska EA, Alvarez-Saavedra E, Townsend M, Yoshii A, Sestan N, Rakic P, Constantine-Paton M, Horvitz HR (2004) Microarray analysis of microRNA expression in the developing mammalian brain. Genome Biol 5:R68.

Moreau MP, Bruse SE, David-Rus R, Buyske S, Brzustowicz LM (2011) Altered microRNA expression profiles in postmortem brain samples from individuals with schizophrenia and bipolar disorder. Biol Psychiatry 69:188-193.

Murphy KC, Jones LA, Owen MJ (1999) High rates of schizophrenia in adults with velo-cardio-facial syndrome. Arch Gen Psychiatry 56:940-945.

Nestler EJ, Hyman SE (2010) Animal models of neuropsychiatric disorders. Nat Neurosci 13:1161-1169.

Oskarsdóttir S, Vujic M, Fasth A (2004) Incidence and prevalence of the 22q11 deletion syndrome: a population-based study in Western Sweden. Arch Dis Child 89:148-151.

Perkins DO, Jeffries CD, Jarskog LF, Thomson JM, Woods K, Newman MA, Parker JS, Jin J, Hammond SM (2007) microRNA expression in the prefrontal cortex of individuals with schizophrenia and schizoaffective disorder. Genome Biol 8:R27.

Pulver AE, Nestadt G, Goldberg R, Shprintzen RJ, Lamacz M, Wolyniec PS, Morrow B, Karayiorgou M, Antonarakis SE, Housman D (1994) Psychotic illness in patients diagnosed with velo-cardio-facial syndrome and their relatives. J Nerv Ment Dis 182:476-478.

Ryan AK, et al (1997) Spectrum of clinical features associated with interstitial chromosome 22q11 deletions: a European collaborative study. J Med Genet 34:798-804.

Scambler PJ (2000) The 22q11 deletion syndromes. Hum Mol Genet 9:2421-2426.

Scambler PJ, Kelly D, Lindsay E, Williamson R, Goldberg R, Shprintzen R, Wilson DI, Goodship JA, Cross IE, Burn J (1992) Velo-cardio-facial syndrome associated with chromosome 22 deletions encompassing the DiGeorge locus. Lancet 339:1138-1139.

Schofield CM, Hsu R, Barker AJ, Gertz CC, Blelloch R, Ullian EM (2011) Monoallelic deletion of the microRNA biogenesis gene Dgcr8 produces 
deficits in the development of excitatory synaptic transmission in the prefrontal cortex. Neural Dev 6:11.

Siegel G, et al (2009) A functional screen implicates microRNA-138dependent regulation of the depalmitoylation enzyme APT1 in dendritic spine morphogenesis. Nat Cell Biol 11:705-716.

Smalheiser NR (2008) Synaptic enrichment of microRNAs in adult mouse forebrain is related to structural features of their precursors. Biol Direct 3:44.

Stark KL, Xu B, Bagchi A, Lai WS, Liu H, Hsu R, Wan X, Pavlidis P, Mills AA, Karayiorgou M, Gogos JA (2008) Altered brain microRNA biogenesis contributes to phenotypic deficits in a 22q11-deletion mouse model. Nat Genet 40:751-760.

Stefansson H, et al (2008) Large recurrent microdeletions associated with schizophrenia. Nature 455:232-236.

Tamminga CA, Stan AD, Wagner AD (2010) The hippocampal formation in schizophrenia. Am J Psychiatry 167:1178-1193.

Thomson JM, Newman M, Parker JS, Morin-Kensicki EM, Wright T, Ham- mond SM (2006) Extensive post-transcriptional regulation of microRNAs and its implications for cancer. Genes Dev 20:2202-2207.

Vandecaetsbeek I, Vangheluwe P, Raeymaekers L, Wuytack F, Vanoevelen J (2011) $\mathrm{The} \mathrm{Ca}^{2+}$ pumps of the endoplasmic reticulum and Golgi apparatus. Cold Spring Harb Perspect Biol 3.

Wang X, El Naqa IM (2008) Prediction of both conserved and nonconserved microRNA targets in animals. Bioinformatics 24:325-332.

Weinberger DR (1999) Schizophrenia: new phenes and new genes. Biol Psychiatry 46:3-7.

Xu B, Roos JL, Levy S, van Rensburg EJ, Gogos JA, Karayiorgou M (2008) Strong association of de novo copy number mutations with sporadic schizophrenia. Nat Genet 40:880-885.

Zolotukhin S, Byrne BJ, Mason E, Zolotukhin I, Potter M, Chesnut K, Summerford C, Samulski RJ, Muzyczka N (1999) Recombinant adenoassociated virus purification using novel methods improves infectious titer and yield. Gene Ther 6:973-985. 